\title{
Recent Advances in Unveiling the Role of Beta-Herpesviruses in Autoimmune Diseases
}

\author{
Maria Cristina Arcangeletti ${ }^{1}$ (D) and Elisabetta Caselli ${ }^{2, *}$ (D) \\ 1 Department of Medicine and Surgery, University of Parma, 43126 Parma, Italy; \\ mariacristina.arcangeletti@unipr.it \\ 2 Section of Microbiology, Department of Chemical, Pharmaceutical and Agricultural Sciences and LTTA, \\ University of Ferrara, 44121 Ferrara, Italy \\ * Correspondence: csb@unife.it; Tel.: +39-0532-455387
}

check for

updates

Citation: Arcangeletti, M.C.; Caselli, E. Recent Advances in Unveiling the Role of Beta-Herpesviruses in Autoimmune Diseases.

Microorganisms 2021, 9, 2572.

https: / / doi.org/10.3390/

microorganisms 9122572

Received: 3 December 2021

Accepted: 9 December 2021

Published: 13 December 2021

Publisher's Note: MDPI stays neutral with regard to jurisdictional claims in published maps and institutional affiliations.

Copyright: (c) 2021 by the authors. Licensee MDPI, Basel, Switzerland. This article is an open access article distributed under the terms and conditions of the Creative Commons Attribution (CC BY) license (https:// creativecommons.org/licenses/by/ $4.0 /)$.
A dysregulated immune response can lead to recognition of self-antigens as non-selfantigens, leading to failure of the immune tolerance toward normal cells and tissues, and the consequent development of a variety of autoimmune diseases. Such diseases stem from a complex interaction between factors including the genetic background and environmental factors which can act as triggers of the dysregulated immune response, finally leading to tissue attack and loss of function or direct destruction.

Autoimmune diseases affect up to $5 \%$ of the general population and include more than 80 chronic and progressive diseases, most of which are without recognized causes and specifically targeted therapies [1].

Among environmental triggers, herpesvirus infection is reportedly associated with the development of autoimmunity, including alpha- (Herpes simplex type 1, HSV-1), beta- (Human cytomegalovirus, HCMV, and Roseoloviruses), and gamma-herpesviruses (Epstein Barr virus, EBV) [2-6], based on their frequent presence in the affected patients and on the detection of specific and/or dysregulated immune response toward them [7].

In particular, beta-herpesvirus sub-family, including Human Cytomegalovirus (HCMV) and the Roseoloviruses Human herpesvirus-6A (HHV-6A), -6B (HHV-6B), and -7 (HHV-7), includes ubiquitous viruses with a long double strand DNA genome encoding more than 200 open reading frames, some of which produce factors that are able to directly interact with and modulate the immune response. Indeed, they have evolved an arsenal of immunomodulatory proteins and miRNAs, with several genes that are homologous to cell genes, most of which affect immune-related processes or controlling immune cell apoptosis [8]. All of them establish lifelong infections in the host, thanks to their ability to persist in a latent phase and eventually reactivate in specific cells.

These characteristics, together with their wide cell/tissue tropism, render beta-herpesviruses good candidates as etiological agents of autoimmune diseases. However, a causative link between virus infection and autoimmune disease onset has not been conclusively established yet, nor the research has clarified whether those viruses are initiators of autoimmune diseases or simply bystanders, exacerbating the course of the pathology.

In addition, beta-herpesviruses have mutualistic relationships and often are found co-reactivated in the host [7,9-11]; co-reactivation is associated with worse clinical outcome.

Recently, the putative role of HCMV and HHV-6 infection has been investigated in autoimmune diseases, such as systemic sclerosis [12-15], multiple sclerosis [16,17], systemic lupus erythematosus [18], and Hashimoto's Thyroiditis [19].

Nevertheless, though research studies have put light on several aspects of the betaherpesvirus replication and potential pathogenesis, no studies on the possible cooperation between beta-herpesviruses have been accomplished, nor has a clear-cut role been established for each individual virus in any of the hypothesized associated autoimmune diseases. 
Furthermore, being beta-herpesviruses considered poorly pathogenic viruses, the research program historically suffered from underfunding to the benefit of other more virulent viruses or more urgent pathologies. For instance, beta-herpesvirus infection could also play a role in the current viral pandemic in relation to the COVID-19 severity in patients with autoimmune diseases. In fact, a higher prevalence of symptomatic SARSCoV-2 infection has been detected among patients with autoimmune systemic diseases, such as systemic sclerosis [20]. In critically ill patients with COVID-19, a significantly high incidence of HCMV and HHV-6 reactivation was observed [21-23].

In this issue, the contributions from leading authors may provide:

- A comprehensive update on the status of the research on beta-herpesvirus and autoimmune diseases;

- Insight into serum or tissue markers of beta-herpesvirus infection;

- Studies highlighting the implementation of immunological and functional assays to understand the role of beta-herpesviruses in the etiopathogenesis of autoimmune diseases;

- Studies describing methods which can be used to distinguish HHV-6A from HHV-6B responses.

The impact of deepening our understanding of the mechanisms by which betaherpesvirus can switch on the onset or the development of autoimmune diseases may help to reduce the risk to contract, slow, or block the progression of such diseases, opening the way for new, advanced therapies that are targeted to virus replication, viral products, or virus-induced factors inside the body.

Taken together, this collection of reports will help to improve such understanding, ultimately expediting the design of appropriate diagnostic and therapeutic tools.

Funding: The authors acknowledge the support of the grants from "Ministero dell'Istruzione, dell'Università e della Ricerca—Progetti di Rilevante Interesse Nazionale (PRIN) 2015" (PI: Maria Cristina Arcangeletti, grant number D92F16000490005; PI: Elisabetta Caselli, grant number 2015YZB22C), HHV-6 Foundation grant (PI: Elisabetta Caselli) and FAR 2020 (PI: Elisabetta Caselli).

Acknowledgments: We would like to acknowledge all authors for their contributions to this Special Issue. We also thank the reviewers for their help in improving the papers to the highest standard of quality as well as the staff members of the Microorganisms Editorial Office for their assistance.

Conflicts of Interest: The authors declare no conflict of interest.

\section{References}

1. Temajo, N.O.; Howard, N. The mosaic of environment involvement in autoimmunity: The abrogation of viral latency by stress, a non-infectious environmental agent, is an intrinsic prerequisite prelude before viruses can rank as infectious environmental agents that trigger autoimmune diseases. Autoimmun. Rev. 2014, 13, 635-640.

2. Yu, Q.; Chu, L.; Li, Y.; Wang, Q.; Zhu, J.; Wang, C.; Cui, S. miR-23a/b suppress cGAS-mediated innate and autoimmunity. Cell Mol. Immunol. 2021, 18, 1235-1248.

3. Bello-Morales, R.; Andreu, S.; López-Guerrero, J.A. The Role of Herpes Simplex Virus Type 1 Infection in Demyelination of the Central Nervous System. Int. J. Mol. Sci. 2020, 21, 5026.

4. Ascherio, A.; Munger, K.L. EBV and Autoimmunity. Curr. Top. Microbiol. Immunol. 2015, 390, 365-385.

5. Halenius, A.; Hengel, H. Human cytomegalovirus and autoimmune disease. Biomed. Res. Int. 2014, 2014, 472978.

6. Broccolo, F.; Fusetti, L.; Ceccherini-Nelli, L. Possible role of human herpesvirus 6 as a trigger of autoimmune disease. Sci. World J. 2013, 2013, 867389 .

7. Cruz-Munoz, M.E.; Fuentes-Panana, E.M. Beta and gamma human herpesviruses: Agonistic and antagonistic interactions with the host immune system. Front. Microbiol. 2017, 8, 2521.

8. Holzerlandt, R.; Orengo, C.; Kellam, P.; Alba, M.M. Identification of new herpesvirus gene homologs in the human genome. Genome Res. 2002, 12, 1739-1748.

9. Lautenschlager, I.; Linnavuori, K.; Lappalainen, M.; Suni, J.; Hockerstedt, K. Hhv-6 reactivation is often associated with cmv infection in liver transplant patients. Transpl. Int. 2000, 13 (Suppl. 1), S351-S353.

10. Lopez Roa, P.; Hill, J.A.; Kirby, K.A.; Leisenring, W.M.; Huang, M.L.; Santo, T.K.; Jerome, K.R.; Boeckh, M.; Limaye, A.P. Coreactivation of human herpesvirus 6 and cytomegalovirus is associated with worse clinical outcome in critically ill adults. Crit. Care Med. 2015, 43, 1415-1422. 
11. Fastenackels, S.; Bayard, C.; Larsen, M.; Magnier, P.; Bonnafous, P.; Seddiki, N.; Appay, V.; Gautheret-Dejean, A.; Sauce, D. Phenotypic and functional differences between human herpesvirus 6- and human cytomegalovirus-specific t cells. J. Virol. 2019, 93, e02321-18.

12. Soffritti, I.; D’Accolti, M.; Ravegnini, G.; Arcangeletti, M.C.; Maccari, C.; De Conto, F.; Calderaro, A.; Caselli, E. Modulation of micrornome by human cytomegalovirus and human herpesvirus 6 infection in human dermal fibroblasts: Possible significance in the induction of fibrosis in systemic sclerosis. Cells 2021, 10, 1060.

13. Arcangeletti, M.C.; Maccari, C.; Vescovini, R.; Volpi, R.; Giuggioli, D.; Sighinolfi, G.; De Conto, F.; Chezzi, C.; Calderaro, A.; Ferri, C. A paradigmatic interplay between human cytomegalovirus and host immune system: Possible involvement of viral antigen-driven cd8+ $\mathrm{t}$ cell responses in systemic sclerosis. Viruses 2018, 10, 508.

14. Caselli, E.; Soffritti, I.; D'Accolti, M.; Bortolotti, D.; Rizzo, R.; Sighinolfi, G.; Giuggioli, D.; Ferri, C. Hhv-6a infection and systemic sclerosis: Clues of a possible association. Microorganisms 2019, 8, 39.

15. Arcangeletti, M.C.; D’Accolti, M.; Maccari, C.; Soffritti, I.; Conto, F.; Chezzi, C.; Calderaro, A.; Ferri, C.; Caselli, E. Impact of human cytomegalovirus and human herpesvirus 6 infection on the expression of factors associated with cell fibrosis and apoptosis: Clues for implication in systemic sclerosis development. Int. J. Mol. Sci. 2020, 21, 6397.

16. Thakolwiboon, S.; Zhao-Fleming, H.; Karukote, A.; Pachariyanon, P.; Williams, H.G.; Avila, M. Regional differences in the association of cytomegalovirus seropositivity and multiple sclerosis: A systematic review and meta-analysis. Mult. Scler. Relat. Disord. 2020, 45, 102393.

17. Mechelli, R.; Romano, C.; Reniè, R.; Manfrè, G.; Buscarinu, M.C.; Romano, S.; Marrone, A.; Bigi, R.; Bellucci, G.; Ballerini, C.; et al. Viruses and neuroinflammation in multiple sclerosis. Neuroimmunol. Neuroinflamm. 2021, 8. [CrossRef]

18. Choo, H.M.C.; Cher, W.Q.; Kwan, Y.H.; Fong, W.W.S. Risk factors for cytomegalovirus disease in systemic lupus erythematosus (sle): A systematic review. Adv. Rheumatol. 2019, 59, 12.

19. Caselli, E.; D'Accolti, M.; Soffritti, I.; Zatelli, M.C.; Rossi, R.; Degli Uberti, E.; Di Luca, D. Hhv-6a in vitro infection of thyrocytes and $t$ cells alters the expression of mirna associated to autoimmune thyroiditis. Virol. J. 2017, 14, 3.

20. Ferri, C.; Giuggioli, D.; Raimondo, V.; Dagna, L.; Riccieri, V.; Zanatta, E.; Guiducci, S.; Tavoni, A.; Foti, R.; Cuomo, G.; et al. COVID-19 and systemic sclerosis: Clinicopathological implications from italian nationwide survey study. Lancet Rheumatol. 2021, 3, e166-e168.

21. Simonnet, A.; Engelmann, I.; Moreau, A.S.; Garcia, B.; Six, S.; El Kalioubie, A.; Robriquet, L.; Hober, D.; Jourdain, M. High incidence of epstein-barr virus, cytomegalovirus, and human-herpes virus-6 reactivations in critically ill patients with COVID-19. Infect. Dis. Now 2021, 51, 296-299.

22. Moss, P. "The ancient and the new": Is there an interaction between cytomegalovirus and sars-cov-2 infection? Immun. Ageing 2020, 17, 14 .

23. Söderberg-Nauclér, C. Does reactivation of cytomegalovirus contribute to severe COVID-19 disease? Immun. Ageing 2021, 18, 12. 